\title{
Scanning Electron Microscopic Evaluation of Debris and Smear Layer after Use of Revo-S and CMA Instruments in Straight Root Canals
}

\section{Zouiten $S^{1}$, Jemâa $\mathrm{M}^{\star 2}$ and Dagna $\mathrm{A}^{3}$}

${ }^{1}$ Professor, Department of Dental Medicine, EPS Farhat Hached, Sousse, Tunisia

${ }^{2}$ Assistant Professor, Department of Dental Medicine, Military Principal Hospital of Instruction, Tunis, Tunisia

${ }^{3}$ Assistant Professor, Department of Clinical, Surgical, Diagnostic and Pediatric Sciences, School of Dentistry, Section of Endodontics, University of Pavia, Italy

*Corresponding author: Jemâa M, Assistant Professor, Department of Dental Medicine, Military Principal Hospital of Instruction, Tunis, Tunisia, Tel: 0021696888820, Fax: 0021672233055, E-mail: dr.jemaamayada@ gmail.com

Citation: Zouiten S, Jemâa M, Dagna A (2015) Scanning Electron Microscopic Evaluation of Debris and Smear Layer after Use of Revo-S and CMA Instruments in Straight Root Canals. J Dent Oral Care Med 1(3): 302. doi: 10.15744/2454-3276.1.302

Received Date: August 28, 2015 Accepted Date: November 04, 2015 Published Date: November 05, 2015

\begin{abstract}
Aim: To compare the cleanliness of root canal walls are following instrumentation with Revo-S and CMA using scanning electron microscopy SEM.
\end{abstract}

Materials and Methods: 30 single-rooted human maxillary incisors with straight root canals freshly extracted for periodontal reasons were selected. Selected teeth were divided into two equal groups and prepared with Revo-S and CMA endodontic instruments. Irrigation was performed with $2.5 \% \mathrm{NaOCl}, 17 \%$ EDTA solutions and final rinse with saline solution. The roots were split into two halves with a chisel and all the canals examined using SEM. The presence of debris (at 350x magnification) and smear layer (at 1500x magnification) was recorded at coronal, middle and apical thirds of root canals using a 4-point scoring system. Data were evaluated statistically using the $\mathrm{T}$ test of independent specimens and significance was predetermined at $\mathrm{P}<0.05$.

Results: None of the two groups achieved completely debrided root canals. In the coronal and middle thirds, the canal walls were clean, with no or only small areas of debris and smear layer. In the apical region, higher scores in terms of debris and smear layer were found. There were no significant differences between the two groups in smear layer and debris removal throughout the three portions of the root canal walls $(\mathrm{P}>0.05)$.

Conclusion: In this study significant differences were not found between the root canals shaped with Revo-S and CMA NiTi rotary instruments. Both instruments produced a clean and debris-free dentine surface in the coronal and middle third, but were unable to produce dentine surfaces free from smear layer in the apical third.

Keywords: Smear layer; Dentinal debris; Irrigation; NiTi instruments; $\mathrm{CMA}^{\oplus}$; Revo-S ${ }^{\oplus}$; SEM

\section{Introduction}

Biomechanical preparation, disinfection and obturation all together constitute equally important phases of the endodontic treatment [1]. Root canal treatment is based on cleaning, shaping and sealing the root canal system. Its main objectives are the elimination of residual pulp tissue, infected dentine and debris and the reduction of the number of microorganism from root canal system [2,3]. Many nickel-titanium (NiTi) rotary instruments have been introduced in the last years. All these endodontic files produce dentine debris and a smear layer as a consequence of their action on root canal walls [4]. Debris contains vital and/or necrotic pulp tissue and dentinal chips that loosely attach to the root canal walls; it is usually infected [2]. The smear layer consists of dentine particles, remnants of vital or necrotic pulp tissues, bacterial components, and retained irrigants [5]. The smear layer is reported to prevent the penetration of irrigating solutions, medications and filling materials into dentinal tubules and many researchers believe that it is detrimental [6]. The design features of the cutting blade of endodontic instruments are important and may affect the cleansing efficiency of the instruments: as a rotary reamer works in a canal, the dentinal debris needs to be removed quickly and effectively [7]. Irrigation plays a key role in successful debridement and removing smear layer during preparation. Sodium hypochlorite $(\mathrm{NaOCl})$ is an irrigant solution widely used in root canal treatment because of its antibacterial properties and ability to dissolve organic tissue. However, it's not effective in removing the inorganic smear layer. Ethylenediaminetetraacetic acid (EDTA) as a chelating agent can remove the smear layer [8]. Thus, a combination of $\mathrm{NaOCl}$ and EDTA has been reported to be suitable for removing both the organic tissue and the inorganic smear layer $[9,10]$. EDTA acts upon the inorganic components of the smear layer and decalcifies the peri- and intertubular dentine and leaves the collagen exposed. Subsequently, the use of $\mathrm{NaOCl}$ dissolves the collagen, cleaning the dentinal walls [9]. Combined use of irrigating solutions and rotary instruments decreases 
bacterial counts in the root canal when compared to standard instrumentation alone [10,11]. The scanning electron microscope has proved to be a valuable method in the comparison of the remaining debris and smear layer on root canal wall after preparation with different instruments: several SEM studies revealed that NiTi rotating instruments associated to EDTA and NaOCl irrigation leave dentine surfaces substantially free from smear layer $[12,13]$. The combination of $\mathrm{NaOCl}$ and EDTA favorites the removal of smear layer and the removal of a great portion of circumferential dentinal collagen and mineralized dentine from the surfaces of tubules, as confirmed by Foschi, et al. [13]. This means that absence of smear layer and presence of clean dentinal walls provide a reduction in bacterial count. An adequate mechanical NiTi instrumentation combined with chemical irrigation greatly reduces the microorganisms remaining in the root canal system [14]. Total removal of smear layer facilitates the diffusion of the irrigants and the medications to the root canal system [15] and then improves the adaptation of the filling materials to the root canal dentine, reducing apical and coronal microleakage of the root canal filling materials [6]. Investigations have shown that different morphology designs of rotary NiTi instruments result in variation in their debris removal and smear layer production $[1,7,16]$. The aim of the present study was to compare by SEM the debris and smear layer remaining on canal walls after preparation with Revo-S (Micro Mega, Besancon, France) and CMA ${ }^{\oplus}$ (CFPM, Tremblay-en-France, France) NiTi instruments in straight root canals. The amount of debris and the morphology of smear layer were parameters for the evaluation of the cleanliness of root canals.

\section{Materials and Methods}

\section{Selection of root canals}

Thirty freshly extracted human single-rooted maxillary incisors, extracted for periodontal reasons, were selected. The teeth with curvature lower than $20^{\circ}$ were chosen because the degree of canal curvature was determined using the Schneider method [7]. The inclusion criteria were: morphological similarity, single-canal root, absence of root decay and absence of previous endodontic treatment, root length of at least $15 \mathrm{~mm}$ and maximum apical diameter of ISO size \#20. The crown of each tooth was removed at the level of the cementum-enamel junction in order to obtain similar root segments of approximately $14 \mathrm{~mm}$ in length (The purpose is to obtain root segments similar in length). Two parallel longitudinal grooves were prepared on the mesial and distal surfaces with a diamond bur, in order to facilitate vertical splitting with a chisel after canal instrumentation. The grooves were not deep enough to enter the canals. Patency of the apical foramina was standardized by inserting a $15 \mathrm{~K}$-file (FKG, La chaux-de-Fonds, Switzerland) so that the tip was just visible. Individual working length was calculated $1 \mathrm{~mm}$ short of this position. Teeth with apical diameters larger than size 15 were excluded from this study.

\section{Canal preparation}

Samples were prepared with two different instruments:

- Group 1 ( $\mathrm{n}=15)$ : Revo-S (Micro Mega, Besancon, France);

- Group 2 ( $\mathrm{n}=15)$ : CMA (CFPM, Tremblay-en-France, France)

Canals of both groups were irrigated during instrumentation and between each file change with $10 \mathrm{ml}$ of $2.5 \% \mathrm{NaOCl}$ solution followed by $2 \mathrm{ml}$ of 17\% EDTA solution left in situ for 3 minutes and by saline solution as a final rinse to remove any effects of irrigants. Then, the canals were dried with paper points.

The irrigating solutions were frequently replaced to maintain their effectiveness. All irrigation procedures were delivered with a 27 gauge endodontic needle (Molteni Dental, Firenze, Italy). The irrigation needle was placed as far apically as possible without binding in the canal. The irrigation procedure was passive. A 20:1 reduction hand piece (W\&H Dentalwerk Bürmoos GmbH, Bürmoos, Austria) powered with a torque-controlled electric motor (Tecnika Digital Torque Control Motor: ATR S.r.l., Pistoia, Italy) was employed for both instrumentation groups with a constant rotation of 300 r.p.m and recommended torque of $0.8 \mathrm{~N} / \mathrm{cm}$.

The Revo-S instrumentation was completed according to the manufacturer's instructions. All canals were sequentially prepared to the apical size of 30 . The first instrument used was SC1 (25-.06) at 2/3 WL, than the SC2 (25.04) and the SU (25.06) at WL. Finishing procedures were completed with the Revo-S AS30 (30-06) used at WL.

The CMA sequence used corresponded to the manufacturer's instructions. All canals were sequentially prepared to the apical size of 30. The preparation sequence required six files, in the sequent order: Coronal 25.08 Instrument used at 1/3 WL; Median 25.06 Instrument used at 2/3 WL; Apical Fine A1 20.04 Instrument used at WL; Apical Fine A2 20.06 Instrument used at WL; Median 25.06 Instrument used at WL; Apical Fine A3 30.06 Instrument used at WL. All canals were prepared by the same trained operator, an endodontic specialist.

\section{SEM preparation}

Each sample was split into two halves with a stainless steel chisel. The sections were prepared for SEM analysis: they were dehydrated in graded concentration of alcohol (70\%, 80\%, 90\%, and 100\%), dried with a critical point drier, gold sputtered and observed with SEM. Photomicrographs of the cervical, the middle and the apical third of each canal with a magnification of 350x (for debris score) and 1500x (for the smear layer) were taken for final evaluation. In a blind manner, one investigator (Professor in Endodontics) scored the presence or absence debris and smear layer on the surface of the root canal at the coronal, middle, and apical portion of each canal. 


\section{Scoring system}

The cleanliness of each root was evaluated at three areas (coronal, middle and apical) by means of a numerical evaluation scale scoring system consisting of following 4 criteria [8].

Scores for the superficial debris:

- Score 1: Absent

- Score 2: Minimal presence of pulpal-fibrous debris

- Score 3: Partial presence of pulpal-fibrous debris

- Score 4: Presence of an organized collagenous matrix

Scores for the smear layer:

- Score 1: Absent, more than 75\% of tubules exposed and free from smear layer. Tubules completely opened.

- Score 2: Present in limited areas, less than 75\% of tubules uncovered. Tubules partially opened

- Score 3: Present, tubules visible in limited areas and partially closed. Less than $50 \%$ of dentinal tubules visible.

- Score 4: Homogeneous smear layer present above all dentin. Dentinal tubules not visible.

\section{Analysis of Data}

Data were plotted in the SPSS Statistics (Developer(s) IBM Corporation, Ver. 17, license: proprietary software, statistical analysis) program and analyzed with the $\mathrm{T}$ test of independent specimens, at a significance level of $\mathrm{P}<0.05$.

\section{Results}

The mean scores of debris and smear layer between groups recorded at coronal, middle and apical thirds are shown in Tables 1 and 2. Completely cleaned root canals were not found after instrumentation with any of both instruments [9]. Debris and smear layer were observed after instrumentation in both groups and in all three parts of the root canal. The instrumented canal walls from both groups appeared smooth and exhibited varying amounts of remaining debris and smear layer along the entire length of the root canal. In the coronal and middle thirds, the canal walls of both instrumentation groups were clean, with no debris or only few debris particles. No smear layer or only small areas of smear layer were observed.

\begin{tabular}{|l|l|l|l|l|l|l|l|l|l|l|l|l|l|}
\hline & \multicolumn{4}{|c|}{ Coronal third scores } & \multicolumn{4}{c|}{ Middle third scores } & \multicolumn{5}{c|}{ Apical third scores } \\
\hline & 1 & 2 & 3 & 4 & 1 & 2 & 3 & 4 & 1 & 2 & 3 & 4 \\
\hline Revo- $S^{\bullet}$ & 9 & 6 & 0 & 0 & 9 & 5 & 1 & 0 & 7 & 7 & 1 & 0 \\
\hline CMA $^{\circ}$ & 8 & 7 & 0 & 0 & 10 & 5 & 0 & 0 & 6 & 7 & 2 & 0 \\
\hline P values & \multicolumn{4}{|c|}{$<0.05$} & \multicolumn{4}{c|}{$<0.05$} & \multicolumn{7}{c|}{$<0.05$} \\
\hline
\end{tabular}

Table 1: Summary for Debris scores *

\begin{tabular}{|l|l|l|l|l|l|l|l|l|l|l|l|l|l|}
\hline & \multicolumn{4}{|c|}{ Coronal third scores } & \multicolumn{4}{c|}{ Middle third scores } & \multicolumn{3}{c|}{ Apical third scores } \\
\hline & 1 & 2 & 3 & 4 & 1 & 2 & 3 & 4 & 1 & 2 & 3 & 4 \\
\hline Revo- $S^{\bullet}$ & 0 & 12 & 3 & 0 & 1 & 13 & 1 & 0 & 0 & 11 & 2 & 2 \\
\hline CMA $^{\bullet}$ & 1 & 13 & 1 & 0 & 0 & 11 & 4 & 0 & 0 & 5 & 10 & 0 \\
\hline P values $^{4}<0.05$ & \multicolumn{4}{c|}{$<0.05$} & \multicolumn{5}{c|}{$<0.05$} \\
\hline
\end{tabular}

Table 2: Summary for smear layer scores*

${ }^{*}$ Listed are the numbers of canal areas evaluated as scores $1-4(\mathrm{n}=15$ teeth per group). Three canal areas (coronal, middle and apical thirds) have been evaluated per tooth, thus resulting in a total 90 canal areas per tooth. Score 1 indicates the best and score 4 the worst result
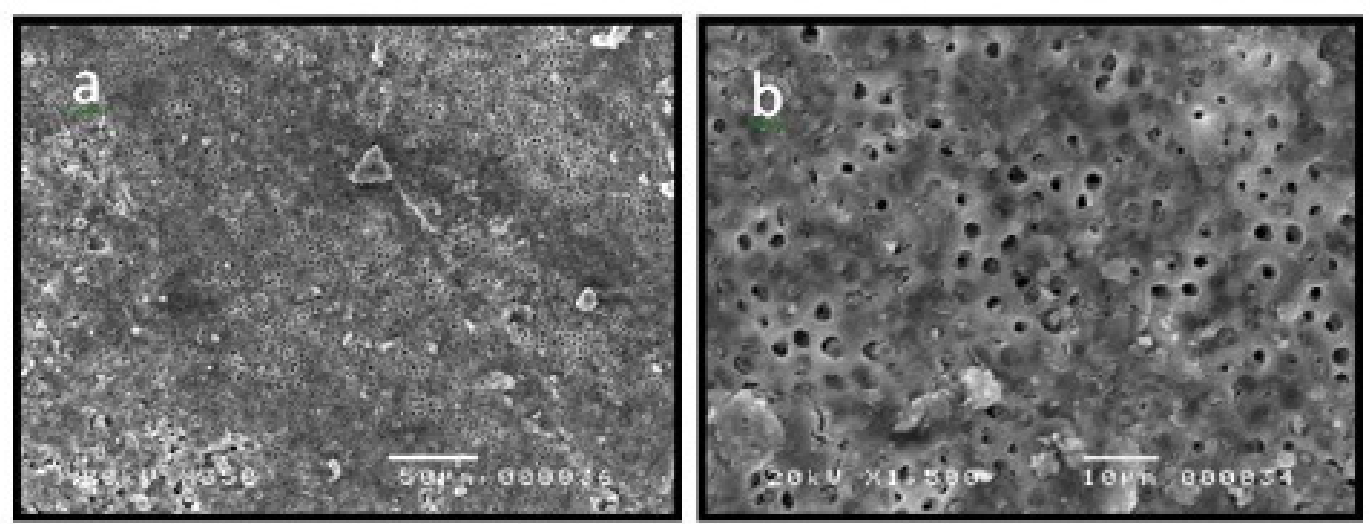

Figure 1: SEM images of root canal walls from group1 $\left(\right.$ Revo- $\left.S^{\varpi}\right)$ in the coronal third $\left(\mathrm{a} \times 350^{*}\right)\left(\mathrm{b} \times 1500^{* *}\right)$ 
The orifices of the dentinal tubules were clearly visible and open (Figures a, b, c, d, g, h, i and l). There were no significant differences between the two instrumentation groups at the corresponding canal parts $(\mathrm{P}>0.05)$. In the apical region, there were higher amounts of debris and smear layer in both instrumentation groups compared to the coronal and middle regions (Figures $\mathrm{e}, \mathrm{f}, \mathrm{m}$ and $\mathrm{n})$. Differences between the two systems were no significant in the apical third concerning residual debris and smear layer $(\mathrm{P}>0.05)$.
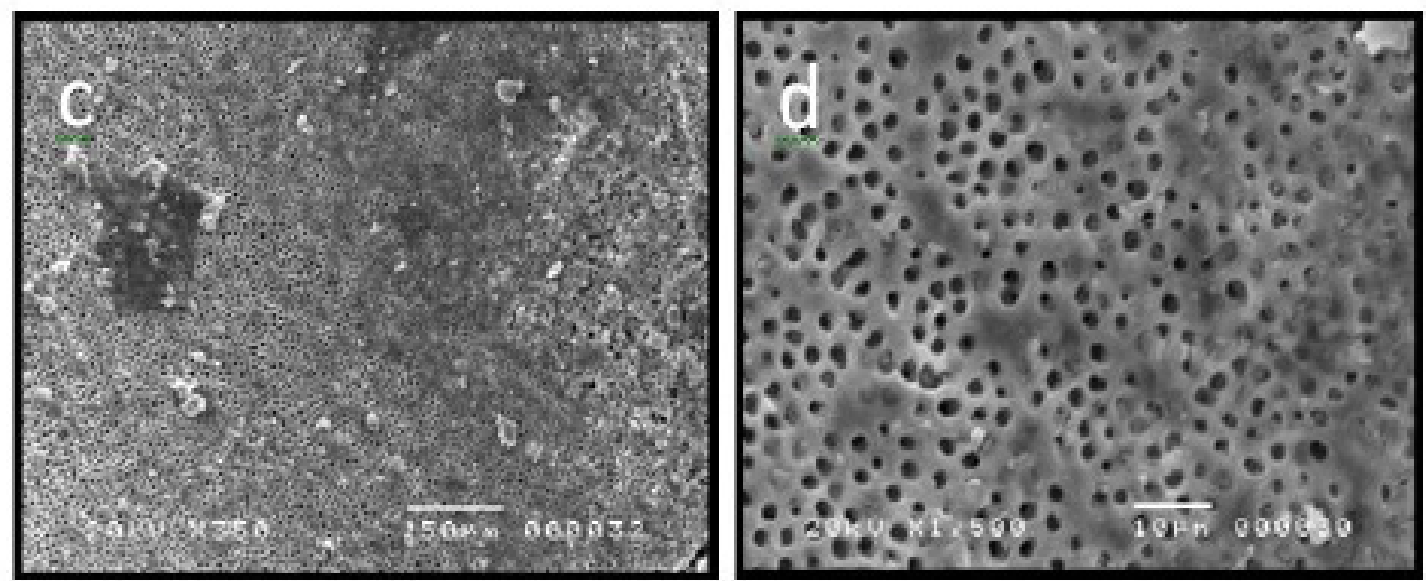

Figure 2: SEM images of the middle portion of the prepared canal with group $1\left(\right.$ Revo- $\left.S^{\star}\right)$, original magnification $\left(\mathrm{c} \times 350^{*}\right)\left(\mathrm{d} \times 1500^{* *}\right)$
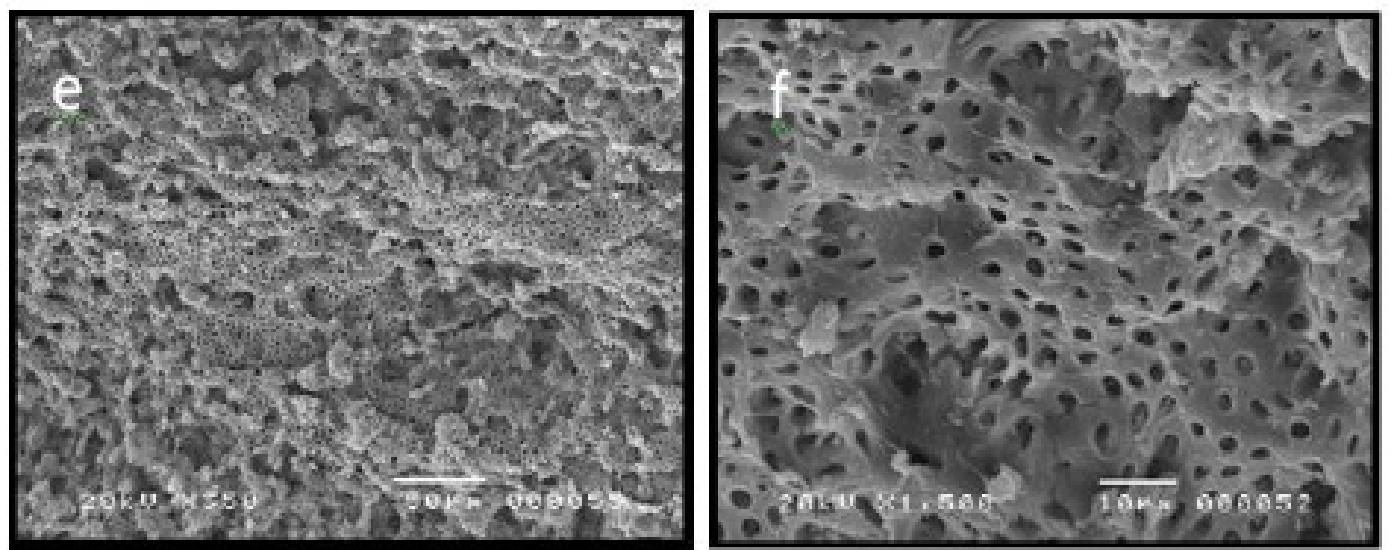

Figure 3: SEM images of the apical portion of the prepared canal with group 1 (Revo-S ${ }^{\star}$ ), original magnification $\left(\mathrm{e} \times 350^{*}\right)\left(\mathrm{f} \times 1500^{* *}\right)$
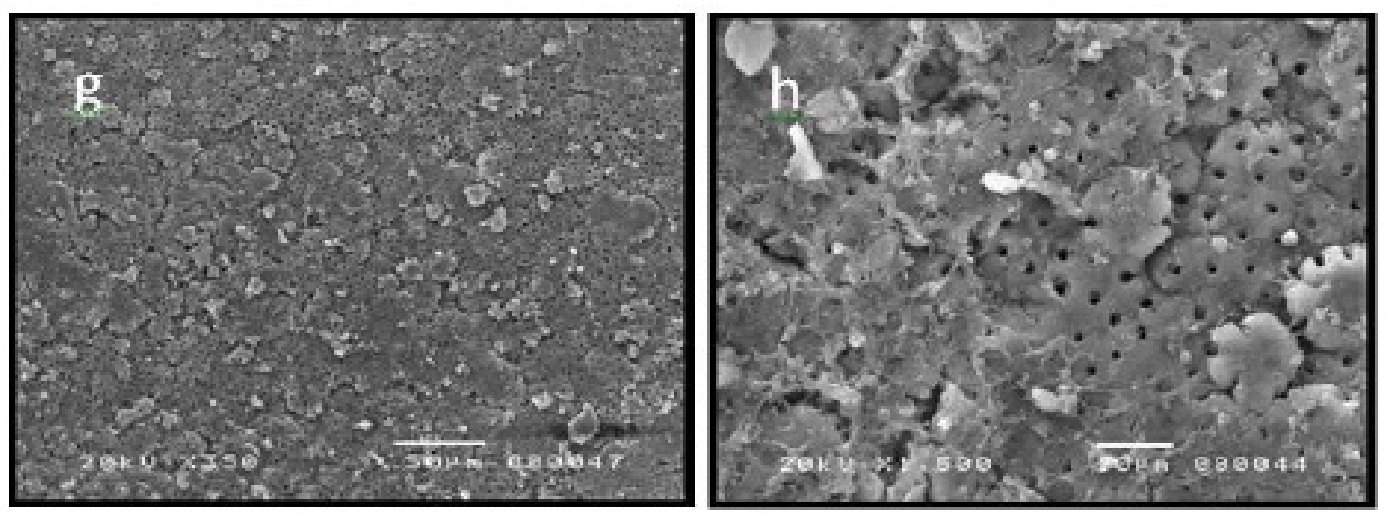

Figure 4: SEM images representative of the coronal portion of the prepared canal with group 2 $\left(\mathrm{CMA}^{\star}\right)$, original magnification $\left(\mathrm{g} \times 350^{*}\right)\left(\mathrm{h} \times 1500^{* *}\right)$ 

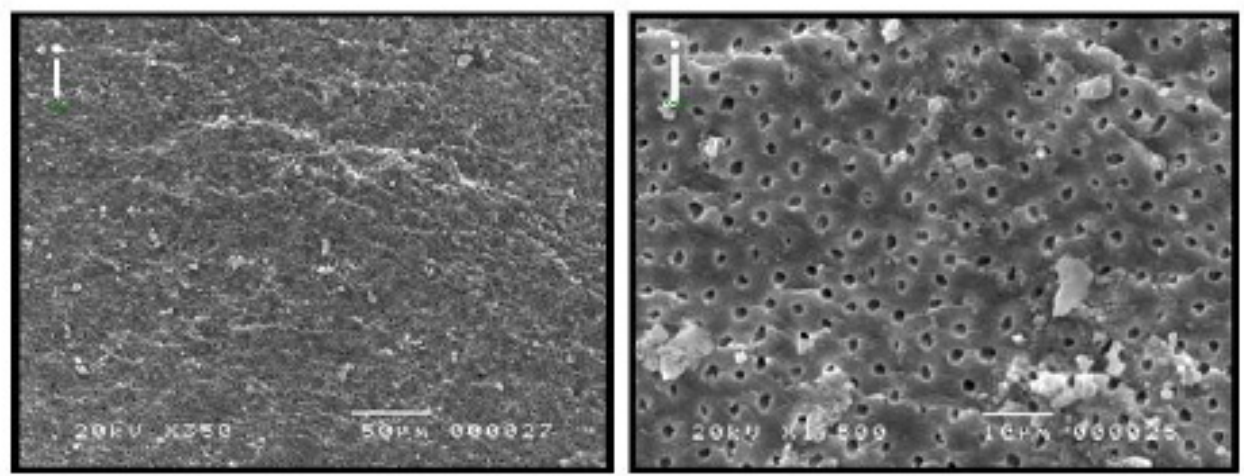

Figure 5: SEM images representative of the middle surface of the prepared canal with group $2\left(\mathrm{CMA}^{\circ}\right)$, original magnification $\left(\mathrm{i} \times 350^{*}\right)\left(\mathrm{j} \times 1500^{* *}\right)$
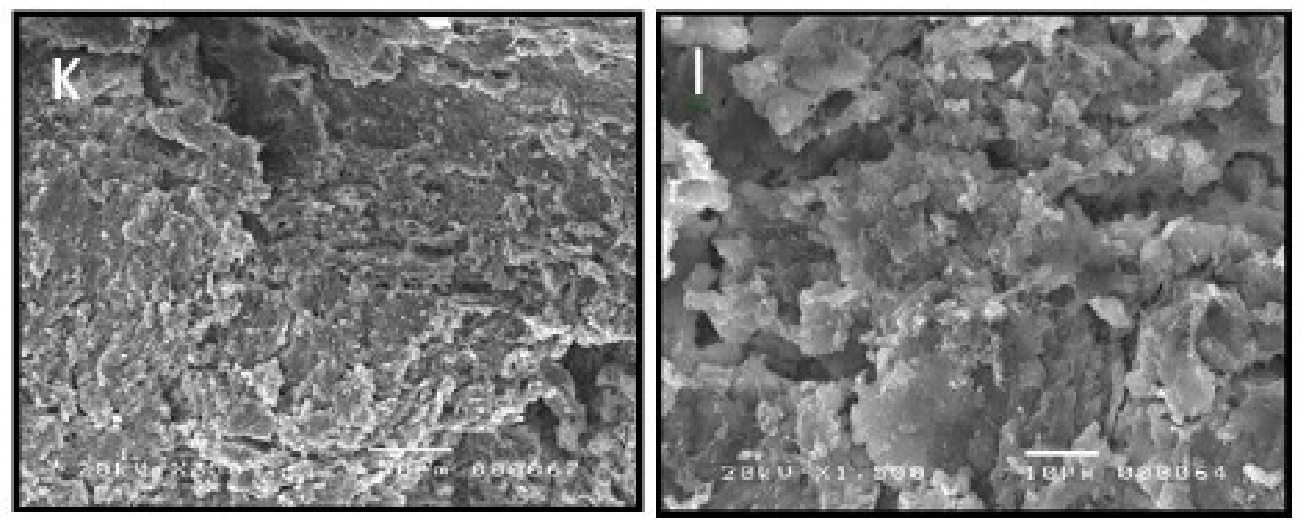

Figure 6: SEM images representative of the apical third of the canal prepared with group $2\left(\mathrm{CMA}^{\circ}\right)$, original magnification $(\mathrm{k}$ $\left.\times 350^{*}\right)\left(1 \times 1500^{* *}\right)$

${ }^{*}$ For the presence of debris

${ }^{* *}$ For the presence smear layer

\section{Discussion}

In this study root canal shaping was performed in extracted human teeth. However, extreme care was shown during the selection of the experimental teeth to reduce the number of anatomical variations. Another methodology for the assessment of root-canal shaping technique is the use of acrylic blocks. Simulated root canals allow standardization of root canal diameter, root canal length and radius of the canal curvature. On the contrary, the hardness and abrasion behavior of acrylic resin and root dentine may not be identical. Despite variations in the morphology of the natural teeth, efforts were made to ensure comparability of the experimental groups. For example, the teeth in both groups were balanced with respect to the angle, length, and dimensions [17]. The present study used human teeth although these can show large variations in dentine hardness and root canal morphology. Their use seems to be the only way to evaluate the cleaning ability of a preparation technique. The SEM technique produces images of high resolution and magnification [8]. However, only the surface can be examined, and the depth of debris cannot be determined precisely. Preparation of the specimen may also induce artefacts [18]. Another weakness of the evaluation of the micrograph was that the measurements of debris and smear layer were arbitrary and at best ordinal in nature. And there is currently no consensus in the standardization of measurements of debris and smear layer [18]. At low magnification (350x) large amounts of debris can easily be seen, but details such as remnants of the smear layer or identification of dentinal tubules need higher magnification (1500x). A disadvantage of using higher magnification is the small size of the area of evaluation, potentially leading to misinterpretation [2]. Another important fact that needs to be emphasized is that efficient cleaning does not necessarily depend only on the type of instrument or instrumentation technique used. In order to dissolve debris and smear layer, chemical irrigation solutions are recommended along with mechanical instrumentation [18]. In our study we used the combination $\mathrm{NaOCl}$ and EDTA because it was recommended by different Authors [3,5,19-24]. Baumgartner and Mader [25] found that alternating solutions of EDTA with $\mathrm{NaOCl}$ was the most effective combination to produce clean root canal walls. Their study demonstrated the importance of using a chelating agent such as EDTA in combination with $\mathrm{NaOCl}$, to effectively remove the inorganic and organic components of the smear layer. However, this did not produce the expected smear-free surface in the apical third of the canal $[9,18,19]$. The concentration of $\mathrm{NaOCl}$ used in our study was $2.5 \%$ according to different studies $[2,15,25]$ and the concentration of EDTA was $17 \%$ which was suggested by different Authors $[6,15,21]$. Final rinse was made with saline solution to neutralize any erosion after use of EDTA [19]. The results showed that the coronal and the middle third of each canals prepared using both systems by crown-down technique method were significantly cleaner when compared with the apical third. No debris or only few debris particles and no smear layer or only small areas of smear layer were observed. 
The reasons for this could be:

- Unique design of Revo-S and CMA instruments, asymmetrical cross section concerning the Revo-S and equilateral cross section concerning the CMA causing efficient cutting in the coronal and middle third.

- Both instruments have a larger taper (4\% and 6\% for the Revo-S and 6\% and 8\% for the CMA) which allow effective shaping and cleaning due to good cutting contact and to continuous smooth funnel shape, that may allow penetration of needle and irrigating solution and sufficient irrigation flow that might have allowed more removal of smear layer and debris during biomechanical preparations procedures [22].

- Positive rake angles of instruments cut more efficiently than neutral or negative rake angles, which scrape the inside of the root canal.

The present results indicate that apical third of all root canals was significantly less clean than the middle and coronal thirds regardless of the instrument used [5,15]. The apical part of the root canal is very difficult to clean because of its dimension, which can prevent effective penetration of irrigating solutions [3]. Predentine, dentine grooves and depressions were observed in the apical thirds on both groups. Their presence suggests that several areas of dentine were not cut and shaped by these instruments. It is possible that the greater number of wall irregularities of this portion of canal such as depression and grooves may be responsible for the presence of uninstrumented areas $[4,15]$.

These observations are in agreement with other studies which showed the limited efficiency of all instruments in cleaning the apical part of the root canal [3,4,5,15-27]. In this study, apical instrumentation was performed with a 30 size file with 0.06 taper [28]. The use of a larger file would be more liable to remove a greater portion of smear layer and debris from the apical thirds [4]. The penetration of irrigants to the apical third of canals may depend on the final size of the instrument used in the canals: Yang, et al. [5] recommends using larger apical taper to optimize irrigation in this area. The increased taper allowed for deeper penetration of the irrigation solution and improved flushing of debris and smear layer. Also the use of activated irrigation may optimize the cleaning of the apical third of each canal [29].

\section{Conclusion}

Within the limitations of this study, the use of Revo-S and CMA instruments in combination with NaOCl and EDTA solutions produced a clean and debris-free dentine surface in the coronal and middle thirds. On the contrary, these instruments were unable to produce a dentine surface free from smear layer and debris in the apical third. Complete cleanliness was not achieved by any of the techniques and instruments investigated.

\section{References}

1. Hülsmann M, Schade M, Schäfers F (2001) A comparative study of root canal preparation with HERO 642 and Quantec SC rotary Ni-Ti instruments. Int Endod J 34: 538-46.

2. Rahimi S, Zand V, Shahi S, Shakaouie S, Reyhani MF, et al. (2008) A comparative scanning electron microscope investigation of cleanliness of root canals using hand K-Flexofiles, rotary RaCe and K3 instruments. Iran Endod J 3: 123-8.

3. Garip Y, Sazak H, Gunday M, Hatipoglu S (2010) Evaluation of smear layer removal after use of a canal brush: an SEM study. Oral Surg Oral Med Oral Pathol Oral Radiol Endod 110: e62-6.

4. Foschi F, Nucci C, Montebugnoli L, Marchionni S, Breschi L, et al. (2004) SEM evaluation of canal wall dentine following use of Mtwo and ProTaper NiTi rotary instruments. Int Endod J 37: 832-9.

5. Yang G, Wu H, Zheng Y, Zhang H, Li H, et al. (2008) Scanning electron microscopic evaluation of debris and smear layer remaining following use of ProTaper and Hero Shaper instruments in combination with $\mathrm{NaOCl}$ and EDTA irrigation. Oral Surg Oral Med Oral Pathol Oral Radiol Endod 106: e63-71.

6. Yiğit Özer S, Adigüzel Ö, Kaya S (2011) Removal of debris and smear layer in curved root canals using self-adjusting file with different operation times - a scanning electron microscope study. Int Dent Res 1: 1-6.

7. Jeon IS, Spångberg LS, Yoon TC, Kazemi RB, Kum KY (2003) Smear layer production by 3 rotary reamers with different cutting blade designs in straight root canals: a scanning electron microscopic study. Oral Surg Oral Med Oral Pathol Oral Radiol Endod 96: 601-7.

8. Giovannone T, Foschi F, Nucci C, Ferrari M, Gallottini L (2006) SEM evaluation of root canal walls after hybrid preparation with NiTi rotary instruments and four different irrigation techniques. Int Dent 8: 38-47.

9. Wadhwani KK, Tikku AP, Chandra A, Shakya VK (2011) A comparative evaluation of smear layer removal using two rotary instrument systems with ethylenediaminetetraacetic acid in different states: a SEM study. Indian J Dent Res 22: 10-5.

10. Radcliffe CE, Potouridou L, Qureshi R, Habahbeh N, Qualtrough A, et al. (2004) Antimicrobial activity of varying concentrations of sodium hypochlorite on the endodontic microorganisms Actinomyces israelii, A. naeslundii, Candida albicans and Enterococcus faecalis. Int Endod J 37: 438-46.

11. Dagna A, Arciola CR, Florindi F, Scribante A, Saino E, et al. (2011) In vitro evaluation of antimicrobial efficacy of endodontic irrigants. Int J Artif Organs 34: 914-9.

12. Foschi F, Nucci C, Montebugnoli L, Marchionni S, Breschi L, et al. (2004) SEM evaluation of canal wall dentine following use of M two and Protaper NiTi rotary instruments. Int Endod J 37: 832-9.

13. Pérez-Heredia M, Ferrer-Luque CM, González-Rodríguez MP (2006) The effectiveness of different acid irrigating solutions in root canal cleaning after hand and rotary instrumentation. J Endod 32: 993-7.

14. Dagna A, Arciola CR, Visai L, Selan L, Colombo M, et al. (2012) Antibacterial efficacy of conventional and single-use Ni-Ti endodontic instruments: an in vitro microbiological evaluation. Int J Artif Organs 35: 826-31. 
15. Kaptan F, Sert S, Kayahan B, Haznedaroğlu F, Tanalp J, et al. (2005) Comparative evaluation of the preparation efficacies of HERO Shaper and Nitiflex root canal instruments in curved root canals. Oral Surg Oral Med Oral Pathol 100: 636-42.

16. Schäfer E, Schlingemann R (2003) Efficiency of rotary nickel-titanium K3 instruments compared with stainless steel hand K-Flexofile. Part 2. Cleaning effectiveness and shaping ability in severely curved root canals of extracted teeth. Int Endod J 36: 208-17.

17. Zand V, Bidar M, Ghaziani P, Rahimi S, Shahi S (2007) A comparative SEM investigation of the smear layer following preparation of root canals using nickel titanium rotary and hand instruments. J Oral Sci 49: 47-52.

18. Unal GC, Maden M, Savgat A, Onur Orhan E (2009) Comparative investigation of 2 rotary nickel-titanium instruments: Protaper Universal versus Protaper. Oral Surg Oral Med Oral Pathol 107: 886-92.

19. Drukteinis S, Balciuniene I (2006) A Scanning electron microscopic study of debris and smear layer remaining following use of AET instruments and Kflexofiles. Stomatologija 8: 70-5.

20. Torabinejad M, Khademi AA, Babagoli J, Cho Y, Johnson WB (2003) A new solution for the removal of the smear layer. J Endod 29: 170-5.

21. Vaudt J, Bitter K, Kielbassa AM (2007) Evaluation of rotary root canal instruments in vitro: a review. Endo 1: 189-203.

22. Dhanyakumar NM, Shivanna V, Garg S (2010) SEM evaluation of smear layer formation after using three different nickel titanium rotary instruments-Endowave, K3 and Protaper: An in vitro study. Endodontology 22: 29-38.

23. Johal S, Baumgartner JC, Marshall JG (2007) Comparison of the antimicrobial efficacy of 1.3\% NaOCl/BioPure MTAD to 5.25\% NaOCl/15\% EDTA for root canal irrigation. J Endod 33: 48-51.

24. Violich DR, Chandler NP (2010) The smear layer in endodontics: a review. Int Endod J 43: 2-15.

25. Baumgartner JC, Mader CL (1987) A scanning electron microscopic evaluation of four root canal irrigation regimens. J Endod 13: 147-57.

26. Veltri M, Mollo A, Pini PP, Ghelli LF, Balleri P (2004) In vitro comparison of shaping abilities of ProTaper and GT rotary files. J Endod 30: 163-6.

27. Metzger Z, Teperovich E, Cohen R, Zary R, Paqué F, et al. (2010) The Self-adjusting File (SAF). Part 3: Removal of Debris and Smear Layer -A Scanning Electron Microscope Study. J Endod 36: 697-702.

28. Usman N, Baumgartner JC, Marshall JG (2004) Influence of instrument size on root canal debridement. J Endod 30: 110-2.

29. Khademi A, Yazdizadeh M, Feizianfard M (2006) Determination of the minimum instrumentation size for penetration of irrigants to the apical third of root canal systems. J Endod 32: 417-20. 